https://doi.org/10.26593/jihi.v16i1.3297.69-86

\title{
Kebijakan Kriminalisasi LGBT Malawi di Tengah Pengaruh Kelompok Kepentingan dan Politik Bantuan Luar Negeri
}

\author{
Puguh Toko Arisanto ${ }^{1} \&$ Tiffany Setyo Pratiwi ${ }^{2}$ \\ ${ }^{1}$ Fakultas Bisnis, Psikologi dan Komunikasi, Universitas Teknologi Yogyakarta, Indonesia, ptas002@gmail.com \\ ${ }^{2}$ Fakultas Bisnis, Psikologi dan Komunikasi, Universitas Teknologi Yogyakarta, Indonesia, \\ tiffany.pratiwi@staff.uty.ac.id
}

\begin{abstract}
Abstrak
Isu LGBT mulai menggelegar di Malawi pada tahun 2009 pasca penangkapan pasangan homoseksual yang tertangkap mengadakan pernikahan. Kriminalisasi didasarkan pada pasal-pasal di KUHP Malawi. Tahun 2010, pemerintah Malawi juga menambah pasal di KUHP untuk mengkriminalisasi lesbian. Namun pasca pergantian Presiden tahun 2012, Presiden pengganti, Joyce Banda menangguhkan kebijakan kriminalisasi pelaku LGBT guna menunggu untuk dikaji ulang oleh Parlemen. Di tengah masa penangguhan, tahun 2015, di bawah Presiden yang berbeda, Malawi mengeluarkan UU kriminalisasi pelaku LGBT melalui Marriage, Divorce and Family Relations Act. Penulis melihat bahwa terjadi inkonsistensi tindakan pemerintah Malawi dalam menerapkan kebijakan kriminalisasi LGBT. Pemerintah Malawi menerapkan kebijakan kriminalisasi LGBT berdasarkan KUHP Malawi, tahun 2012 menangguhkannya, dan kemudian 2015 kembali mengeluarkan kebijakan kriminalisasi LGBT melalui UU. Artikel ini hendak memaparkan peran kelompok kepentingan yang saling bertentangan (conflicting interest groups) antara religious leaders dan NGO domestik beserta politik "stick and carrot" dalam bantuan luar negeri negara-negara pendonor di Malawi. Variabel-variabel tersebut menjadi pokok analisis yang mempengaruhi inkonsistensi penerapan kebijakan kriminalisasi LGBT di Malawi.
\end{abstract}

Kata Kunci: kriminalisasi LGBT; KUHP Malawi; inkonsistensi; kelompok kepentingan; stick and carrot.

\begin{abstract}
Issues of LGBT boomed in Malawi in 2009 after an arrest of homosexual couple who held a wedding party. The criminalization was based on Malawi's Penal Code. In 2010, Malawian government also added an article on the Penal Code to criminalize lesbians. However, after the succession of Malawi President in 2012, the successor president, Joyce Banda suspended the policy criminalizing LGBT to await a review of the Parliament. Amid the suspension, under a different President, on April 2015 Malawi passed an LGBT Act of criminalization through Marriage, Divorce and Family Relations Act. The authors note that there had been an inconsistency of the Malawi government in applying policy criminalizing LGBT. The government implemented the policy of criminalization towards LGBT based on Malawi Penal Code, suspended it in 2012, and then 2015 re-issued policy criminalizing LGBT through certain act. This article explores the roles of conflicting interest groups between religious leaders and domestic NGO followed by politics "stick and carrot" on foreign aid of donor states in Malawi. These variables are subjects to analysis that affect the inconsistency of Malawi government to implement the policy.
\end{abstract}

Keywords: criminalizing LGBT; Penal Code; inconsistency; interest groups; stick and carrot 


\section{PENDAHULUAN}

Malawi adalah negara miskin bekas koloni Inggris yang merdeka pada tahun 1964. Negara ini mayoritas dihuni oleh pemeluk Kristen (Protestan, Katolik dan sekte lainnya) yang mencapai $86 \%$ sedangkan $12 \%$ berasal dari Islam. Negara yang 2/3 Gross Domestic Bruto (GDP) dan $80 \%$ pendapatan ekspornya berasal dari sektor pertanian ini sangat mengandalkan bantuan luar negeri (foreign aid) baik dari organisasi internasional seperti IMF, Bank Dunia dan European Union (EU) maupun negara-negara besar seperti Inggris, Amerika Serikat (AS), Jerman dan sebagainya $^{1}$. Bahkan $40 \%$ dari anggaran pembiayaan pembangunan pemerintah Malawi berasal dari bantuan luar negeri. Global Policy Forum memaparkan bahwa negara-negara miskin di Afrika (salah satunya adalah Malawi) yang membutuhkan bantuan luar negeri adalah negara-negara dengan permasalahan sosial ekonomi yang kompleks mulai dari masalah penyakit seperti HIV/AIDS, kemiskinan, pemerintah yang korup hingga tingkat kematian yang tinggi. ${ }^{2}$

Dalam konteks politik hukum regional, Malawi adalah satu dari 36 negara Afrika yang melarang adanya hubungan sesama jenis. Pelarangan hubungan sesama jenis menimbulkan perhatian publik yang luas dari berbagai media baik domestik maupun mancanegara dan menjadi polemik di lingkungan domestik Malawi sendiri. Isu lesbian, gay, biseksual dan transgender $(\text { LGBT })^{3}$ mulai mengemuka di Malawi pada

\footnotetext{
1 "The World Factbook: Malawi," Central Intelligence Agency (Central Intelligence Agency, Februari 1, 2018), diunduh

https://www.cia.gov/library/publications/the-worldfactbook/geos/mi.html.

${ }^{2}$ Global Policy Forum (2014, 16 Juli). Development aid to Africa diunduh dari, https://www.globalpolicy.org/social-and-economicpolicy/poverty-and-development/poverty-anddevelopment-in-africa.html

${ }^{3}$ Lesbian adalah perempuan yang orientasi seksualnya kepada sesama perempuan, Gay atau disebut juga
}

akhir tahun 2009. Ini diawali ketika Polisi Malawi mengkriminalisasi dengan menangkap pasangan sejenis yaitu Steven Monjeza dan Tiwonge Chimbalanga yang menikah dengan menggunakan tradisi Malawi. Penangkapan dilakukan karena kedua pasangan tersebut terbukti melakukan perbuatan tidak senonoh sesama lelaki (indecent practices between males) berdasarkan Penal Code atau Kitab Undang-Undang Hukum Pidana (KUHP) Malawi. Selain itu, perbuatan tersebut juga bertentangan dengan nilai dan norma yang dianut oleh mayoritas penduduk Malawi. Dengan kata lain, keduanya dinilai melakukan perbuatan kriminal menentang hukum, kebudayaan, dan agama negara Malawi ${ }^{4}$. Pasangan sejenis tersebut dihukum berupa kerja kasar (hard labour) di dalam penjara selama 14 tahun. Meskipun kemudian, pada faktanya Presiden, Malawi Bingu wa Mutharika membebaskan dan mengampuni pasangan homoseksual tersebut setelah mendapatkan kunjungan dari Sekjen PBB (Perserikatan Bangsa-Bangsa), Ban Ki Moon ${ }^{5}$.

Peristiwa penangkapan pasangan sejenis tahun 2009 tersebut kemudian menyebabkan merebaknya homofobia di kalangan masyarakat Malawi. Apalagi, tidak lama setelah penangkapan pasangan sejenis tersebut, bulan Januari 2010, polisi Malawi kembali mempolisikan pegawai Centre for the Development of People (CEDEP), sebuah NGO (Non Governmental Organization) karena diduga keras memiliki benda-benda pornografi yang identik dengan seks bagi

\footnotetext{
homoseks/homoseksual yaitu laki-laki yang memiliki kecenderungan seksualnya kepada sesama laki-laki, Biseksual adalah orang yang memiliki ketertarikan baik pada sesama maupun lawan jenis, Transgender yaitu orang yang identitas gendernya berbeda dengan identitas seksnya saat lahir.

${ }^{4}$ Philip Browne, Canaries in the Coal Mines : An Analysis for LGBTI Activism in Malawi (pp.7-10). Country Report. Johannesburg: Other Foundation. 2017. ${ }^{5}$ BBC News (2010, 29 Mei). Malawi pardons jailed gay couple. diunduh dari http://www.bbc.com/news/10190653
} 
homoseksual (homosexual gay material). Bulan berikutnya, polisi kembali menangkap seorang pria tua berumur 60 tahun karena melakukan tindakan sodomi dan dihukum 10 tahun penjara meskipun dalam kesaksiannya, pria tua tersebut berdalih hanya tertarik hubungan biologis pada laki-laki bahkan sejak dia lahir 6

Kriminalisasi terhadap pelaku sodomi dan seks sesama jenis atau homoseks bukanlah perkara hukum baru di Malawi. Sejak zaman penjajahan Inggris, kriminalisasi dan stigmatisasi terhadap pelaku sodomi dan homoseks sudah diterapkan di Malawi. Dengan kata lain, legislasi mengenai kriminalisasi pelaku sodomi dan homoseks merupakan warisan dari penjajahan Inggris yang banyak diilhami oleh nilai-nilai moralitas kristiani. Pascakemerdekaan tahun 1964, Malawi masih memegang kuat hukum peninggalan era koloni Inggris tersebut meskipun konstitusi Malawi telah direvisi atau diamandemen dua kali yakni pada masa awal kemerdekaan 1965 dan pada masa munculnya demokrasi multipartai $1995^{7}$.

Sejak awal tahun 2010, di bawah rezim pemerintahan Presiden, Bingu wa Mutharika, penangkapan pasangan sejenis yang melakukan pernikahan menandai kebijakan tegas pemimpin Malawi tersebut terhadap pelaku LGBT. Bingu wa Mutharika menegaskan bahwa penduduk Malawi dilarang meniru budaya asing yang mereka tidak pahami termasuk pernikahan sejenis yang diyakini merupakan tindakan setan yang

\footnotetext{
${ }^{6} \mathrm{~F}$ Namangale. Judge faults tough sentences against gays. The Nation dalam Undule Mwakasungula, The LGBT situation in Malawi : an activist perspective (pp.359-379.) Chapter 13 of Corinne Lennox \& Matthew Waites (Human Rights, Sexual Orientation and Gender Identity in The Commonwealth: Struggles for Decriminalisation and Change. London: School of Advanced Study, University of London. 2013.

${ }^{7}$ Kim Y Dionne dan Boniface Dulani, The Washington Post (2016, 1 Maret). This one graph shows the biggest threat to LGBT rights in Malawi. diunduh dari https://www.washingtonpost.com/news/monkeycage/wp/2016/03/01/this-one-graph-shows-the-biggestthreat-to-lgbt-rights-in-

malawi/?utm_term $=.61 \mathrm{~b} 23 \mathrm{e} 50 \mathrm{c} 29 \mathrm{~b}$
}

dilarang oleh Tuhan ${ }^{8}$. Pascapenangkapan tersebut, isu kriminalisasi dan perlindungan hak LGBT akhirnya menjadi yang sangat sensitif di Malawi dan menjadi objek atensi publik selama bertahun-tahun. Isu LGBT dinilai menjadi isu yang atraktif dalam domestik Malawi karena menyangkut interseksi antara politik domestik dan internasional, agama, hubungan dengan negara-negara dan organisasi donor, aktivis Hak Asasi Manusia (HAM) dan Lembaga Swadaya Masyarakat (LSM), pemerintah Malawi dan masyarakat yang lebih luas? .

Pemberlakuan kriminalisasi pelaku LGBT pada tindakan pernikahan pasangan sejenis dan sodomi tahun 2009-2010 didasarkan pada KUHP 1971 Malawi yang banyak diadopsi dari era penjajahan. KUHP Malawi pasal 153 dan 156 menyatakan bahwa orientasi seksual yang dilakukan oleh pelaku homoseks dan sodomi merupakan perbuatan yang menimbulkan pelanggaran hukum (law offense) sehingga dapat dijatuhi hukuman. Pasal-pasal ini diklaim sangat berpengaruh dan mencabut hak dan kebebasan pelaku LGBT. Pasal 153 dan 156 dalam KUHP Malawi menyatakan bahwa ${ }^{10}$ :

153) Anyone who has carnal knowledge of any person against the order of nature; (b) has carnal knowledge of any animal; or (c) permits a male person to have carnal knowledge of him or her against the order of nature; shall be guilty of a felony and shall be liable to imprisonment for fourteen years, with or without corporal punishment.

156) Any male who, whether in public or private, commits any act of gross indecency with another male person, or procures

\footnotetext{
${ }^{8}$ Rex Chikoko, Mutharika Criticises Gay Movement, Nation Newspaper, diunduh dari http://www.gtzkenyahealth.com/press/downloads/PRESS \%20CLIPPINGS\%2027TH\%20APRIL\%202010.pdf

9 Emmie Chanika, John L. Lwanda dan Adamson S. Muula, Gender, Gays and Gain: The Sexualised Politics of Donor Aid in Malawi (pp.89-105). Africa Spectrum. Vol.48, No.1. 2013.

${ }^{10}$ Antigaylaws, African Countries where Homosexuality is still a Crime. diunduh dari https://antigaylaws.org/regional/africa/
} 
another male person to commit any act of gross indecency with him, or attempts to procure the commission of any such act by any male person with himself or with another male person, whether in public or private, shall be guilty of a felony and shall be liable to imprisonment for five years, with or without corporal punishment'.

Inti dari dua pasal di atas yaitu melarang dan mengkriminalisasi seseorang yang melakukan pelanggaran tak wajar (unnatural offences) seperti sodomi baik dengan sesama laki-laki maupun dengan hewan dengan hukuman 14 tahun penjara baik dengan atau tanpa hukuman fisik dan praktik atau perbuatan tidak senonoh sesama laki-laki (indecent practices between males) baik di depan umum maupun secara sendiri dengan hukuman 5 tahun penjara baik dengan atau tanpa hukuman fisik. Pernikahan pasangan sejenis seperti pada kasus Steven Monjeza dan Tiwonge Chimbalanga tahun 2009 bisa dijerat dengan kedua pasal tersebut.

Pasca penangkapan tahun 2009-2010, aturan hukum pidana yang mengkriminalisasi pelaku sodomi dan homoseksual digugat oleh berbagai aktivis HAM dan LGBT domestik maupun $\quad$ internasional $^{11}$. Alih-alih menghentikan dan merevisi pasal tersebut, tahun 2011 rezim Bingu wa Mutharika justru memperluas cakupan aturan hukum pidana anti LGBT-nya dengan menerbitkan pasal baru mengenai kriminalisasi pelaku lesbian (Indecent practices between females) yang termaktub dalam pasal 137A. Pasal tersebut berbunyi "any female person who, whether in public or private, commits 'any act of gross indecency with another female shall be guilty of an offence and liable to a prison term of five years" 12 . Pasal ini secara jelas melarang hubungan pasangan sejenis antara perempuan dengan perempuan atau lesbian. Pelanggaran pasal tersebut akan dikenakan hukuman

\footnotetext{
${ }^{11}$ Philip Browne, Loc.cit

${ }^{12}$ Refugee Legal Aid Information, Malawi LGBTI Resources. diunduh dari

http://www.refugeelegalaidinformation.org/malawi-lgbtiresources
}

penjara selama 5 tahun dan menimbulkan sebuah kepastian hukum bagi pelaku lesbian untuk dikriminalisasikan. Bagi pihak yang pro LGBT, pasal kriminalisasi untuk lesbian tersebut semakin menyudutkan kaum LGBT dan merupakan langkah mundur di tengahtengah nilai-nilai kemanusiaan global yang mengakui persamaan dan martabat manusia.

Diterbitkannya pasal 137A menjadi bukti bahwa rezim Presiden, Bingu wa Mutharika menentang praktik LGBT yang dianggap sebagai perbuatan menyimpang dari norma agama dan budaya Malawi. Namun akhir tahun 2012, penerapan kebijakan kriminalisasi LGBT di Malawi berubah 180 derajat. Pasca meninggalnya presiden Bingu wa Mutharika yang kemudian digantikan wakilnya, Joyce Banda, kriminalisasi terhadap pelaku LGBT tidak berlaku lagi. Pemerintahan Malawi di bawah rezim Joyce Banda mengubah haluan kebijakan LGBT-nya dari kriminalisasi pelaku LGBT menjadi dekriminalisasi pelaku LGBT. Joyce Banda menegaskan bahwa ketentuan KUHP pasal 153, 156 dan 137A yang mengkriminalisasi pelaku LGBT seperti homoseks dan lesbian sudah seharusnya dicabut ${ }^{13}$. November 2012, Presiden wanita pertama tersebut secara resmi menangguhkan kebijakan kriminalisasi homoseksual dan pasangan sejenis lainnya setelah melalui kajian ulang beberapa bulan. Tindakan Joyce Banda yang dinilai kontroversi oleh sebagian masyarakat Malawi ini, diumumkan oleh Attorney General (Jaksa Agung) dan Menteri Keadilan (Justice Minister) Malawi, Ralph Kasambara yang sekaligus meminta polisi nasional Malawi agar tidak mengkriminalisasi pelaku pasangan sejenis. Kebijakan kriminalisasi ditangguhkan untuk menunggu keputusan review dari Parlemen Malawi ${ }^{14}$. Di bawah rezim

13 International Gay and Lesbian Human Rights Commission. Africa Perspective: Newsletter 2013 (pp.14). New York: IGLHRC. 2013.

14 "Malawi: Courageous Move to Suspend Anti-Gay Laws," Human Rights Watch, November 6, 2012, diunduh 
pemerintahan Joyce Banda yang dianggap moderat ini, pelaku LGBT tidak perlu lagi takut lagi terhadap ancaman kriminalisasi terhadap perilaku atas orientasi seksualnya.

Tidak sampai 3 tahun, di tengah penangguhan kebijakan kriminalisasi LGBT yang berarti tidak berlakunya pasal-pasal KUHP 153. 156 dan 137A, pemerintah Malawi mengubah haluan kebijakan LGBT-nya. Di bawah rezim presiden baru, Peter Mutharika yang terpilih melalui pemilu 2014, kemudian pada bulan April 2015, pemerintah Malawi mengubah kebijakan dari dekriminalisasi pelaku LGBT menjadi kriminalisasi pelaku LGBT. Kali ini pemerintah Malawi melarang hubungan pasangan sejenis tidak dengan mencabut penangguhan pasal-pasal KUHP yang digunakan untuk mengkriminalisasi LGBT tetapi dengan mengeluarkan UU (undang-undang) Pernikahan, Perceraian dan Hubungan Keluarga (Marriage, Divorce and Family Relations Act). UU tersebut selain mengatur mengenai usia minimal pernikahan, perceraian dan perlindungan perempuan juga mengatur larangan pernikahan sejenis, perpaduannya, pernikahan transgender maupun transeksual (ganti kelamin) ${ }^{15}$. Dalam hal ini pemerintah Malawi secara tegas membatasi pernikahan hanya diperuntukkan untuk lakilaki dengan perempuan (opposite sex) atau heteroseksual. Jenis kelamin laki-laki dan perempuan ditentukan berdasarkan kelahiran bukan berdasarkan pada jenis kelamin pascaoperasi ganti kelamin (sex-changing surgery). Selain itu, UU ini juga melarang tidak wajar (unnatural offences) seperti yang termaktub dalam pasal 153 KUHP Malawi. Hubungan homoseks sebagai unnatural offences dapat dianggap sebanding dengan pemerkosaan dan kekerasan seksual. Pelaku pernikahan yang melanggar ketentuan UU tersebut seperti pernikahan sejenis dihukum

https://www.hrw.org/news/2012/11/06/malawicourageous-move-suspend-anti-gay-laws.

15 Home Office, Country Information and Guidance Malawi: Sexual Orientation and Gender Identity (pp.10). UK: Home Office. 2016. berupa denda 100.000 Kwachas (mata uang Malawi) dan penjara selama lima tahun ${ }^{16}$.

Berdasarkan fakta di atas, penulis berargumen bahwa terdapat inkonsistensi pemerintah Malawi dalam menerapkan kebijakan kriminalisasi LGBT dari tahun 2009 hingga 2015. Tulisan ini tidak berusaha menyoroti pergantian kepemimpinan sebagai faktor yang menentukan inkonsistensi penerapan kebijakan kriminalisasi LGBT, meskipun faktanya berganti pemimpin berganti pula penerapan kebijakan kriminalisasi LGBT di Malawi. Penulis lebih cenderung menganalisis dinamika konflik kelompok kepentingan yang berkembang di Malawi antara $R L$ dan NGO domestik dan politik bantuan luar negeri negara-negara maju di Malawi. Tiga variabel tersebut menjadi pokok analisis yang mempengaruhi inkonsistensi penerapan kebijakan kriminalisasi LGBT di Malawi.

\section{KERANGKA ANALISIS}

\section{Konsep Interest Groups (Kelompok Kepentingan)}

Interest Groups atau kelompok kepentingan dapat dipahami sebagai sebuah asosiasi yang terorganisir yang bertujuan untuk memengaruhi kebijakan-kebijakan atau aksiaksi dari pemerintah. Kelompok kepentingan bisa juga disebut sebagai pressure groups atau kelompok penekan. Meskipun dalam beberapa hal kelompok kepentingan berusaha menyalurkan aspirasi dan kepentingan masyarakat namun kelompok kepentingan berbeda dengan partai politik karena $:^{17}$

1. Mereka berusaha untuk memengaruhi dari luar daripada masuk menjadi dan ikut dalam penyelenggaraan negara.

\footnotetext{
${ }^{16}$ Lihat juga pada UU Pernikahan, Perceraian dan Hubungan Keluarga Malawi dari website https://www.giRLnotbrides.org/wpcontent/uploads/2015/03/Malawi-Marriage-Divorce-andFamily-Relations-bill-2015.pdf

${ }^{17}$ Andrew Heywood, Politik: Edisi Ke-empat (pp.435). Yogyakarta: Pustaka Pelajar. 2013.
} 
2. Mereka secara khas memiliki fokus isu yang jelas dan sempit. Tujuan dan kepentingan yang dituju pada umumnya berfokus pada satu isu tertentu saja.

3. Mereka jarang memiliki ciri-ciri programik seperti partai politik dan umumnya memiliki gerakan-gerakan sosial dengan organisasi formal yang cakupannya luas.

Winarno $^{18}$ memberikan penjelasan bahwa aktivitas kelompok kepentingan umumnya menyangkut tujuan-tujuan terbatas dengan sasaran-sasaran monolitis dengan institusi yang tidak berlebihan. Sedangkan menurut Ramlan Surbakti $^{19}$, kelompok kepentingan ialah sejumlah orang yang memiliki kesamaan sifat, kepercayaan dan/atau tujuan, yang sepakat mengorganisasikan diri untuk melindungi dan mencapai tujuan. Secara singkat, setidaknya ada beberapa peran kelompok kepentingan dalam proses politik sebuah negara yaitu ${ }^{20}$ Membuat tuntutan kepada pengambil kebijakan (interest articulation),

1. Memainkan penyebaran nilai budaya dan memengaruhi perilaku masyarakat dalam politik (political socialization).

2. Ikut sebagai non-partisan group dalam pemilu.

3. Melobi para pembuat perundang-undangan atau legislasi agar mengeluarkan legislasi yang diinginkan.

4. Memformulasikan opini publik dalam rangka mengevaluasi hukum, peraturan dan kebijakan pemerintah

Dalam tulisannya, Gabriel Almond juga memaparkan bahwa kelompok kepentingan dalam memberikan input kepada pembuat kebijakan biasanya menempuh jalurjalur, seperti: demonstrasi dan tindakan

\footnotetext{
${ }^{18}$ Budi Winarno, Sistem Politik Indonesia Era Reformasi (pp.83). Jakarta: Buku Kita. 2007.

19 Ramlan Subakti, Memahami Ilmu Politik (pp.109). Jakarta: Gramedia Widiasarana Indonesia. 2010.

${ }^{20}$ Saheb D. Shareyouressays, 8 Important Functions and Role of Interest Groups. diunduh dari http://www.shareyouressays.com/knowledge/8-

important-functions-and-role-of-interest-groups/112490
}

kekerasan, baik melalui hubungan pribadi, keluarga atau teman yang memiliki jabatan publik, melalui perwakilan langsung yang mana perwakilan langsung ini memungkinkan suatu kelompok kepentingan untuk mengomunikasikan secara langsung dan berkelanjutan tentang isu-isu yang ingin dicapai kepada perwakilan dalam struktur pemerintahan. Kelompok kepentingan juga sering menggunakan media massa dalam memengaruhi masyarakat dan mengembangkan isu yang diperjuangkan. ${ }^{21}$ Adapun contoh organisasi yang termasuk dalam kelompok kepentingan seperti NGO atau LSM, berbagai asosiasi seperti asosiasi ekonomi, asosiasi/kelompok keagamaan (religious groups), asosiasi profesi dan sejenisnya, serta organisasi-organisasi sosial seperti serikat buruh, himpunan pengusaha, kelompok tani dan sebagainya.

Di era demokrasi saat ini, peran kelompok kepentingan memainkan peran penting dalam proses pengambilan keputusan sebuah negara. Peran kelompok kepentingan seperti NGO dan kelompok-kelompok agama (religious groups) sebagai organisasi, kelompok atau asosiasi yang mengatasnamakan kepentingan masyarakat tidak bisa diabaikan begitu saja. NGO sering kali melibatkan diri dalam berbagai isu dan memiliki pengaruh politik baik ditingkat nasional bahkan internasional. Mereka juga bisa menginternasionalkan sebuah isu dan mengundang aktor-aktor internasional untuk memberikan perhatian pada isu tersebut dalam sebuah negara guna memberikan tekanan kepada pengambil kebijakan negara setempat. Tidak berbeda dengan NGO, religious groups yang dipimpin religious leaders memainkan peran penting dalam proses perumusan kebijakan sebuah negara dalam perspektif agama di sebuah negara. ${ }^{22}$ Mereka dapat

\footnotetext{
${ }_{21}$ Johan Jasin, Hukum Tata Negara Suatu Pengantar (pp.87). Yogyakarta: Deepublish. 2016.

${ }^{22}$ Zoe Robinson, Lobbying in The Shadows: Religious Interest Groups in The Legislative Process (pp. 1045 1047). Emory Law Journal. Vol 64. Issue. 4. 2015.
} 
mempengaruhi pengambil kebijakan melalui berbagai sarana seperti lobi pemerintah, demonstrasi, penyebaran pendapat melalui media massa dan sebagainya.

Dalam praktiknya, perbedaan pandangan antara kelompok kepentingan satu dengan lainnya yang pada gilirannya melahirkan kepentingan yang berbeda pula terjadi dalam proses perumusan kebijakan sebuah negara. Adanya conflicting interests (kepentingan yang berlawanan) antar kelompok kepentingan tidak jarang memengaruhi keputusan yang akan diambil oleh pemerintah. Dalam kondisi ini, idealnya pengambil kebijakan mengakomodasi kepentingan dari kelompok-kelompok kepentingan sehingga menghasilkan keputusan yang merupakan win-win solution atas perbedaan-perbedaan kepentingan yang ada ${ }^{23}$.

\section{Konsep Politik Bantuan Luar Negeri (Foreign Aid Politics)}

Foreign Aid atau bantuan luar negeri dapat diartikan sebagai bantuan yang diberikan suatu negara atau organisasi internasional kepada negara lain berupa bantuan teknis, ekonomi, atau militer untuk tujuan tertentu seperti untuk meringankan beban dan rehabilitasi karena bencana alam dan perang, stabilitasi ekonomi dan pertahanan bersama (mutual defense) ${ }^{24}$. Economic Cooperation and Development (OECD) menyebutkan ada beberapa sektor dalam alokasi bantuan luar negeri yang termasuk dalam Official Development Assistance (ODA) yaitu infrastruktur dan pelayanan sosial, infrastruktur ekonomi, sektor produksi, dana bantuan budgeting, bantuan kemanusiaan, pendanaan multisektor dan bantuan dalam hal utang luar negeri. Di era

\footnotetext{
${ }^{23}$ Puguh T Arisanto, Trade Controversy Amidst Tobacco Control Provisions: Dynamics on The Establishment of U.S Tobacco Control Act 2009 (pp.12.-13). Jurnal Ilmiah Hubungan Internasional. Vol.13, No.2. 2017.

${ }^{24}$ Guljinder K Randhawa, Foreign Aid in Economic Development (pp.1). International Journal of Computing \& Business Research. ISSN (Online): 2229-6166. 2012.
}

globalisasi, negara-negara semakin saling ketergantungan, program-program yang didanai dengan bantuan luar negeri semakin menjamur dan semakin lazim di negara-negara miskin $^{25}$. Meskipun begitu, motif kehadiran bantuan luar negeri di negara penerima (recipient country) perlu dipahami lebih mendalam.

Dikaitkan dengan kebijakan luar negeri, bantuan luar negeri dapat dijadikan sebagai instrumen dalam mewujudkan tujuan kebijakan luar negeri sebuah negara. Dalam hal ini, meskipun bantuan luar negeri memiliki beberapa tujuan seperti meningkatkan kesejahteraan manusia, tetapi alasan utama penyaluran bantuan luar negeri bagi negara pendonor tidak lain semata-mata hanya untuk mengejar tujuan kebijakan luar negerinya. Kepentingan komersial dan strategis negaranegara pendonor adalah faktor utama dibalik berbagai macam program bantuan luar negeri. Dalam implementasinya, bantuan dapat ditarik kembali untuk menciptakan kesukaran ekonomi (economic hardship) atau untuk mendestabilisasikan rezim negara penerima yang tidak ramah atau yang bertentangan ideologinya dengan negara pendonor. Selain itu bantuan dapat juga digunakan untuk menyokong dan menghadiahi sebuah rezim pemerintahan tertentu yang patuh pada negara pendonor. ${ }^{26}$ Ini berarti bahwa bantuan luar negeri selain diposisikan sebagai insentif yang membangun kesejahteraan di negara penerima namun juga bisa menjadi ancaman apabila bantuan dihentikan.

Dalam relasinya dengan negara penerima, negara pendonor dapat memanfaatkan bantuan luar negeri sebagai stick and carrot (tongkat

25 Carol Lancaster, Foreign Aid: Diplomacy, Development, Domestic Politics (pp.1). Chicago and London: University of Chicago Press. 2007.

${ }^{26}$ Clair Apodaca, Oxford Research Encyclopedia of Politics (2017, April). Foreign Aid as Foreign Policy. diunduh dari

http://politics.oxfordre.com/view/10.1093/acrefore/97801 90228637.001.0001/acrefore-9780190228637-e332 ?print $=$ pdf 
dan wortel $)^{27}$ yang menggabungkan antara reward (hadiah) dan punishment (hukuman). Jika negara penerima menuruti kemauan dan menyenangkan negara pendonor maka akan diberikan carrot sebagai reward dan sebaliknya ketika negara penerima tidak menuruti atau membangkang, negara pendonor akan menggunakan stick untuk menggebuk sebagai bentuk punishment sehingga negara penerima diharapkan mengubah perilakunya.

Dikaitkan dengan konsep stick and carrot, negara pendonor dapat menjadikan bantuan luar negeri baik sebagai reward atas sebuah tindakan maupun rangsangan untuk mengubah perilaku. Dalam hal ini, negara pendonor dapat mengubah perilaku negara penerima sesuai keinginan dan tujuan negara pendonor melalui bantuan luar negerinya. Ilustrasinya, jika negara penerima menuruti kemauan negara pendonor, negara pendonor akan terus memberikan bantuan luar negerinya sebagai bentuk reward atas kepatuhannya namun jika membangkang negara-negara pendonor dapat memotong atau bahkan menarik bantuan luar negerinya sebagai bentuk punishment atas ketidakpatuhannya. Pemotongan atau penarikan bantuan luar negeri tentu akan menjadi sebuah ancaman bagi negara penerima yang identik dengan negara miskin yang banyak mengandalkan bantuan luar negeri. Dalam posisi ini, negara penerima akan berada dalam posisi dilematis antara menuruti kemauan negara pendonor dengan hadiah bantuan luar negeri atau membangkang dengan hukuman berupa penarikan bantuan luar negeri padahal tidak jarang kepentingan negara penerima tidak sesuai dengan kemauan atau kepentingan negara-negara pendonor.

\section{PEMBAHASAN}

\section{Peran Religious Leaders Malawi Melawan Praktik LGBT}

Ajaran dan nilai-nilai Kristen (khususnya Katolik dan Protestan) mendominasi kehidupan masyarakat Malawi hingga saat ini. Ini diawali ketika Malawi, sama seperti banyak negara Afrika lainnya, mengalami kolonialisasi/penjajahan negara Inggris. Masyarakat Malawi juga sangat mengenal hukum-hukum yang diwariskan oleh Inggris yang sebenarnya juga banyak diilhami oleh nilai-nilai moralitas ajaran Kristen ${ }^{28}$.

Dalam konteks pemerintahan, kehidupan sosial politik dan pembangunan di Malawi tidak bisa dipisahkan dari eksistensi organisasi-organisasi keagamaan yang dipimpin RL. RL dalam hal ini merujuk pada pemuka-pemuka agama Kristen seperti Uskup, Pendeta dan Kardinal. RL beserta organisasiorganisasinya sebagai interest groups telah memainkan peran vital dalam pembangunan Malawi. Banyak sekolah dan rumah sakit dibangun melalui organisasi keagamaan yang dipimpin oleh RL. RL juga terlibat aktif dalam mempromosikan keadilan sosial, demokrasi dan kesejahteraan rakyat ${ }^{29}$. Berdasarkan survei yang dilakukan oleh organisasi Afrobarometer, organisasi-organisasi yang dipimpin RL adalah organisasi yang paling dapat dipercayai oleh masyarakat Malawi $^{30}$ sehingga tidak mengejutkan apabila pendapat atau fatwa dari RL baik sebagai individu maupun sebagai perwakilan organisasi keagamaan dianggap masyarakat sebagai sesuatu yang penting untuk didengarkan dan diikuti. Ini berarti pada dasarnya RL dianggap role model bagi kehidupan Malawi dan memiliki pengikut yang banyak.

\footnotetext{
${ }^{28}$ Emmie Chanika, John L. Lwanda dan Adamson S. Muula., Loc.cit.

${ }^{29}$ China Embassy in Malawi The Role of Religious Leaders in National Development -Keynote Speech by H.E. Ambassador Pan Hejun at the Religious Leaders Workshop of Malawi, Mei 24, 2011, diunduh dari http://mw.chinaembassy.org/eng/sghdhzxxx/t825097.htm

30 Afrobarometer, State of the nation: Malawians'reflections on political governance (pp.9-10). Zomba: University of Malawi. 2017.
} 
Dalam kancah politik domestik, RL baik sebagai individu maupun perwakilan organisasi sering kali mengungkapkan pendapat mereka mengenai isu-isu politik dan pernyataan mereka banyak diterima oleh media Malawi. Organisasi-organisasi RL juga sering menjadi penyalur (conduit) aspirasi masyarakat Afrika termasuk masyarakat Malawi untuk memprotes kebijakan pemerintah. ${ }^{31}$ Selain itu di sisi yang lain, RL dan pemerintah Malawi juga memiliki hubungan yang baik. Dalam hal ini pemerintah Malawi sangat mendengarkan aspirasi dari RL dan organisasi-organisasinya. Beberapa pernyataan di atas, dapat disimpulkan bahwa RL sebagai interest groups memiliki peran besar terhadap berbagai aspek kehidupan negara Malawi.

Dikaitkan dengan LGBT di Malawi, RL yang mengklaim sebagai the soul of nation Malawi telah menentang keras praktik pasangan sejenis dan perpaduannya baik sebelum maupun setelah kemerdekaan. Tindakan tersebut dinilai sangat bertentangan dengan ajaran agama kristen. Tidak haya RL dari Kristen, RL dari agama Islam pun mengutuk tindakan homoseksual. Menurutnya, homoseksual sebagai perbuatan setan, berdosa besar berdasarkan kitab Al Quran. Dikutip dalam sebuah wawancara, perwakilan RL mengatakan agama tidak mengampuni homoseksualitas atau hubungan seks sejenis dan nilai-nilai agama lebih penting dari pada HAM. ${ }^{32}$ PAC (Public Affair Committee) yang beranggotakan RL juga telah mem-branding konsep "God-Fearing Nation" bahwa Malawi adalah negara yang takut dengan Tuhan dan praktik-praktik LGBT seperti homoseksual dianggap sebagai konsep asing yang

\footnotetext{
${ }_{31}$ Alex Thomson. An Introduction to African Politics Third Ed (pp.73). Routledge. 2016.

${ }^{32}$ Manuel Malamba, The Controversy of Homosexuality: A Critical Look at The Issues That Make Legalizing Homosexuality in Malawi Difficult (pp.37). Gothenburg: University of Gothenburg, 2012.
}

menyimpang dari negara dan kebudayaan masyarakat Malawi. ${ }^{33}$

Tindakan kriminalisasi terhadap pasangan sejenis homoseksual tahun 2009 dengan hukum 14 tahun kerja kasar sudah tentu mendapatkan dukungan dari RL Malawi yang memang sejak awal telah menentang dan mengutuk praktik LGBT. RL berada stand point yang sama dengan pemerintah Malawi saat itu bahwa homoseks menentang budaya Malawi, melawan kodrat Tuhan sehingga perlu adanya kriminalisasi terhadap pelakunya ${ }^{34}$. Pascapenangkapan tersebut, dukungan RL agar pemerintah Malawi mempertahankan kebijakan kriminalisasi tersebut bermunculan. Gereja-gereja dan aliansi berbagai gereja yang dipimpin RL mendukung dan meminta pemerintah Malawi mempertahankan kebijakan kriminalisasi tersebut. ${ }^{35}$ Selain itu mereka juga meminta organisasi-organisasi internasional untuk menghargai nilai agama dan budaya Malawi. Dukungan secara individu dari RL juga bermunculan seperti Pemuka agama ternama Malawi, Felix Zalimba menegaskan bahwa "homosexuality is immoral and that two people of the same sex can't have sex and be accepted in society" artinya homoseks adalah tindakan asusila, dilarang dan tidak diterima dalam masyarakat. ${ }^{36}$

Upaya RL yang meminta pemerintah Malawi agar mempertahankan kebijakan kriminalisasi LGBT nampaknya mendapatkan hasilnya hingga awal tahun 2012. Namun di era Joyce Banda, pada bulan November 2012,

\footnotetext{
${ }^{33}$ Lyson Sibande, Malawi Voice, "Five Fallacies against Decriminalisation of Homosexuality in Malawi," Malawi Voice, Mei 19, 2012, diunduh dari http://www.malawivoice.com/2012/05/19/five-fallaciesagainst-decriminalization-of-homosexuality-in-malawi40476/

34. Manuel Malamba, Op.cit.pp 36.

${ }^{35}$ Benny Tsododo, The Herald (2013, 31 Desember). Gay parties Western, Not Human Rights. diunduh dari https://www.herald.co.zw/gay-parties-western-nothuman-rights/

${ }^{36}$ Lameck Masina. VOA (2010, 18 Februari). Malawians Debate Legalizing Gay Marriage. diunduh dari https://www.voanews.com/a/malawians-debate-issue-oflegalizing-gay-marriage--84777977/160359.html
} 
kebijakan kriminalisasi tersebut ditangguhkan. Kondisi ini menyakitkan para RL Malawi karena beberapa bulan sebelumnya, para RL telah memberikan nasihat-nasihat kepada rezim baru Joyce Banda mengenai bagaimana pandangan para RL mengenai pasangan sejenis yang dilarang dalam ajaran agama dan cara mengatasi isu LGBT tersebut. ${ }^{37}$

Merespon penangguhan kebijakan kriminalisasi pasangan sejenis, RL tidak bergeming begitu saja. RL baik secara individu maupun melalui organisasi-organisasinya menentang dengan keras penangguhan kebijakan kriminalisasi LGBT tersebut. Aliansi organisasi RL seperti Council of Churches (kelompok organisasi RL yang terdiri dari 24 Gereja Protestan) dengan keras mendesak Attorney General dan pemerintah Malawi untuk mencabut penangguhan tersebut ${ }^{38}$. RL secara implisit memperingatkan kepada rezim Joyce Banda bahwa RL akan terus menentang kebijakan penangguhan tersebut karena bertentangan dengan nilai agama, moral, dan budaya. ${ }^{39}$ RL telah mencoba melobi dan meminta pemerintahan Joyce Banda agar tidak lunak terhadap tekanan-tekanan internasional khususnya negara-negara barat pendonor Malawi yang menginginkan dekriminalisasi praktik hubungan pasangan sejenis. ${ }^{40}$ Tindakan para RL juga menular kepada masyarakat Malawi yang memprotes pemerintah Malawi seperti dengan mewacanakan bahaya LGBT bagi agama dan budaya Malawi dalam bentuk

\footnotetext{
37 "Religious Leaders tip JB on homosexuality," The Nation, Mei 13, 2012, diunduh dari http://mwnation.com/religious-leaders-tip-jb-onhomosexuality/

38 "Churches force Malawi to change tune on anti-gay law," Reuters, diunduh dari https://www.reuters.com/article/us-malawigays/churches-force-malawi-to-change-tune-on-anti-gaylaw-idUSBRE8A70XJ20121108

${ }^{39}$ Lameck Masina, "Suspension of Anti-gay Law Draws Mixed Reaction in Malawi," Voice of America, diunduh dari https://www.voanews.com/a/suspension-of-anti-gaylaw-draws-mixed-reaction-in-malawi/1541867.html 40 "Malawi 'suspends' anti-homosexual laws," BBC News, Desember 21, 2015, diunduh dari http://www.bbc.co.uk/news/world-africa-35151341
}

petisi. ${ }^{41}$ Meskipun desakan gencar dilakukan hingga diusulkan hingga ke Mahkamah Tinggi Malawi untuk dikaji ulang namun hingga akhir tahun 2015 desakan yang dilakukan oleh RL pada akhirnya tidak menghasilkan pencabutan penangguhan kebijakan kriminalisasi pasangan sejenis di Malawi.

Desakan RL tidak berhenti begitu saja. Pada tahun 2016, RL beserta organisasiorganisasi sayapnya mengadakan long march meminta pemerintah Malawi untuk mencabut penangguhan kebijakan kriminalisasi Homoseks. $^{42}$ Salah satunya adalah Young Pastor Coalition yang mendesak melalui pengadilan tinggi di Malawi dan berargumen bahwa yang memiliki wewenang untuk menangguhkan kebijakan kriminalisasi pasangan sejenis bukanlah pemerintah di tataran eksekutif seperti Presiden, Wakil Presiden maupun Menteri tetapi Parlemen yang merupakan institusi resmi yang mewakili suara rakyat. ${ }^{43}$ Meskipun tahun 2015, pemerintah Malawi di bawah rezim Peter Mutharika mengeluarkan UU Perkawinan, Perceraian dan Hubungan Keluarga sebagai payung hukum untuk menjerat pelaku LGBT yang melakukan pernikahan sejenis namun UU tersebut nampaknya masih belum melegakan RL yang menginginkan pencabutan penangguhan pasal KUHP mengenai pelaku LGBT dan menghendaki pemberlakuan keduanya agar lebih tegas menjerat pelaku LGBT.

Berdasarkan penjelasan di atas, dilihat dalam perspektif HAM, RL meminta pemerintah Malawi untuk melihat HAM sebagai nilai yang universal tetapi

\footnotetext{
41"'Petition against Malawi Govt suspension of antihomosexuality laws." Nyasa Times, November 6, 2012, diunduh dari https://www.nyasatimes.com/petitionagainst-malawi-govt-suspension-of-anti-homosexualitylaws/

42 "Malawi religious leaders march against homosexuality and abortion," Mamba, 8 Desember, 2016. diunduh dari http://www.mambaonline.com/2016/12/08/malawireligious-leaders-march-homosexuality abortion/. 43 "Religious leaders meet with LGBTI community in Malawi," Mamba, 3 Agustus, 2016, diunduh dari http://www.mambaonline.com/2016/08/03/religiousleaders-meet-lgbt-community-malawi/
} 
implementasinya disesuaikan dengan kondisi domestik. Dalam hal ini, masalah-masalah HAM harus dipandang sebagai masalahmasalah internasional maupun nasional dan penerapan nilai-nilai HAM tersebut harus disesuaikan dengan sosial budaya seperti norma-norma, agama dan nilai-nilai budaya masyarakat negara tersebut. Pendekatan ini disebut Particularism approach yang relatif atau pendekatan partikulerisme relatif. ${ }^{44} \mathrm{RL}$ tidak menafikkan bahwa HAM adalah sesuatu yang penting dalam kehidupan, namun implementasi HAM di Malawi harus disesuaikan dengan nilai-nilai sosial budaya Malawi. Implementasi nilai-nilai HAM di negara-negara barat berbeda dengan implementasi HAM di Malawi karena perbedaan latar belakang sosial budaya.

\section{Peran NGO Domestik Malawi dalam Memperjuangkan Hak LGBT}

Sejak penangkapan pernikahan sejenis akhir tahun 2009, isu LGBT menjadi mengudara di domestik Malawi. Pro dan kontra mewarnai berita Malawi dalam isu-isu kemanusiaan. Geliat para aktivis maupun organisasi-organisasi kemanusiaan pro LGBT mulai menampakkan aksinya menentang kriminalisasi yang dilakukan pemerintah. Berkat aksi mereka, isu kriminalisasi LGBT menjadi isu krusial yang mendapatkan perhatian internasional dari NGO internasional, negara-negara besar hingga organisasiorganisasi internasional.

Di Malawi, salah satu NGO yang secara terang-terangan mendukung dan memperjuangkan hak kebebasan LGBT adalah CEDEP. Tahun 2010, CEDEP memberikan perhatian khusus untuk kasus Steven Monjeza dan Tiwonge Chimbalanga setelah mereka mengadakan upacara pernikahan tahun 2009. Saat itu lobi ke pemerintah diupayakan secara

\footnotetext{
${ }^{44}$ Abdullah T Wahyudi, Universalitas dan Partikularitas Hak Asasi Manusia dalam Undang-Undang Nomor 1 Tahun 1974 Tentang Perkawinan (pp.96), Al-Ahkam: Jurnal Ilmu Syariah dan Hukum, Vol. 1. No.1. 2016.
}

terus menerus oleh CEDEP. Selain itu, CEDEP juga tidak ketinggalan meminta dukungan publik masyarakat Malawi. Salah satu dengan membuka donasi yang bisa disalurkan apabila ada masyarakat yang ingin menyumbangkan uangnya untuk mendukung hak-hak LGBT. ${ }^{45}$ Namun, jauh sebelum kasus ini muncul, CEDEP yang terbentuk tahun 2005 ini memang telah memiliki visi menjamin pendidikan dan kesehatan serta dukungan sosial untuk komunitas LGBT khususnya gay di Malawi. CEDEP memulai dukungannya dengan menyediakan sosialisasi pendidikan HIV/AIDS.

Selain beraksi di lingkungan lokal, upaya CEDEP untuk meraih dukungan internasional juga dilakukan bahkan sebelum tahun 2009. CEDEP menjalin kerjasama dengan pihak asing yaitu Skotlandia. Equality Network (EN) Skotlandia bersama CEDEP Malawi mengembangkan sebuah proyek kemitraan untuk mengembangkan hubungan antar negara mengenai hak LGBT dan berbagi pengalaman dan pembelajaran. EN Skotlandia dan CEDEP melakukan proyek kecil yakni pengembangan buklet untuk LGBT di Malawi yang isinya tentang hak-hak LGBT dan juga bekerjasama untuk penanganan AIDS di kalangan LGBT. ${ }^{46}$ Tercatat di tahun 2008 sebuah gerakan mendukung gay di Malawi terbentuk, The Malawi Gay Rights Movement (MAGRIM), sayangnya gerakan ini tenggelam begitu saja. Hal ini karena adanya penolakan gerakan LGBT dari masyarakat Malawi sendiri yang masih besar.

Selain CEDEP, organisasi lain yang mulai muncul ke permukaan pasca penangkapan pelaku LGBT tahun 2009 adalah Malawi

\footnotetext{
"Four African LGBT Organizations Worth Supporting," Advocate, Agustus 11, 2010, diunduh dari https://www.advocate.com/artsentertainment/features/2010/08/11/four-african-lgbtorganizations-worth-supporting

46 “Cross Party Group on Malawi, ” Parliamentscot, Mei 10, 2017, diunduh dari http://www.parliament.scot/CrossPartyGroups/Ses sion5CrossPartyGroup/Minutes/Malawi_2017051 $0 . p d f$
} 
Human Rights Commission (MHRC). Komisi HAM Malawi ini cukup vokal menyuarakan hak-hak LGBT dan menentang keras kriminalisasi yang dilakukan oleh rezim Bingu wa Mutharika. Pascapenangkapan tahun 2009, MHRC melancarkan lobi-lobi politik yang meminta penangguhan atau pencabutan larangan hubungan homoseksual di Malawi. ${ }^{47}$ MHRC mengklaim bahwa kriminalisasi LGBT yang dilakukan pemerintah Malawi bertentangan dengan HAM dan pemerintah Malawi telah melakukan diskriminasi terhadap kaum minoritas.

Upaya yang dilakukan MHRC diperkuat juga oleh Centre for Human Rights and Rehabilitation (CHRR) Malawi. Melalui juru kampanye hak minoritas dan juga Direktur Eksekutif CHRR, Timothy Mtambo mengatakan bahwa posisi peradilan Malawi mengenai masalah homoseksual sangat mengkhawatirkan. CHRR sangat siap untuk mendukung kelompok mana pun yang memiliki pandangan yang sama terkait proses aturan hukum LGBT di Malawi. Mtambo menjelaskan bahwa jika aturan kriminalisasi LGBT diterapkan maka lebih dari 40.000 homoseksual di Malawi akan hidup menderita. ${ }^{48}$

Di samping CEDEP, MHRC dan CHRR yang bertindak aktif mendukung dan memperjuangkan hak-hak LGBT serta menentang kriminalisasi pelaku LGBT, NGO lainnya kemudian juga bermunculan menyuarakan dukungan hak-hak LGBT di Malawi. Adapun NGO yang turut memberikan dukungannya ialah Youth and Children Rights Shield (YOCRIS), Forum for National Development (FND), dan Counseling for the Adolescent Youth Organization (CAYO) telah

\footnotetext{
47 "Public to be asked to give input on gay ban," Mamba, diunduh dari http://www.mambaonline.com/2017/08/14/malawipublic-asked-give-input-lgbti-rights/

${ }^{48}$ Lameck Masina, "Malawi Court Annuls Government

Suspension of Anti-Gay Laws," Voice of America,

diunduh dari https://www.voanews.com/a/malawi-courtannuls-governments-suspension-on-anti-gay-

laws/3188056.html
}

menyatakan minatnya untuk bergabung dengan MHRC dan CEDEP dalam upaya untuk mempromosikan hak semua orang termasuk mereka orang-orang LGBT tanpa diskriminasi.

Berkat aksi-aksi yang dilakukan oleh NGO Malawi dalam memperjuangkan hak-hak LGBT dan menentang kriminalisasi tidak dipungkiri bahwa akibat aksi-aksi tersebut, isu LGBT akhirnya menyita perhatian internasional. Dukungan-dukungan dari pihak asing baik dari state actor maupun non state actor atas tindakan NGO Malawi bermunculan. Dukungan yang berdatangan salah satunya dari International Gay and Lesbian Human Rights Commission (IGLHRC). IGLHRC memberikan dukungan lewat media dan melakukan komunikasi dengan NGO lokal untuk mendukung perjuangan hak-hak LGBT di Malawi ${ }^{49}$. Selain dukungan terhadap NGO Malawi, kecaman internasional terhadap kriminalisasi LGBT di Malawi juga bermunculan. Salah satunya adalah dari PBB. PBB melalui organisasi sayapnya, secara resmi meluncurkan pernyataan perang hukum (court battle) melawan kriminalisasi homoseks yang dilakukan oleh Malawi dan meminta Malawi mencabut kebijakan kriminalisasi pelaku LGBT atas nama HAM yang melarang perbuatan diskriminasi. ${ }^{50}$

Desakan dari NGO lokal Malawi agar mencabut kebijakan kriminalisasi LGBT dan menyebabkan isu LGBT di Malawi menjadi booming secara internasional tentu menjadi masukan penting bagi pemerintah Malawi untuk mempertimbangkan kelanjutan kebijakan kriminalisasi LGBT. Dalam posisi

\footnotetext{
${ }^{49}$ Out Right Action International (2014, 10 Juli). UN Human Rights Committee Identifies Human Rights Violations Against Persons Based on Sexual Orientation in Malawi. diunduh dari https://www.outrightinternational.org/content/un-humanrights-committee-identifies-human-rights-violationsagainst-persons-based-sexual

${ }^{50}$ Mabvuto Banda, "U.N. to launch legal challenge against Malawi anti-gay laws," Reuters, diunduh dari https://www.reuters.com/article/us-malawi-gays/u-n-tolaunch-legal-challenge-against-malawi-anti-gay-lawsidUSBREA0K0H420140121
} 
ini, rezim pemerintah Malawi tidak bisa mengabaikan begitu saja desakan NGO. Mengabaikan desakan NGO akan memperpanjang solidaritas internasional untuk mengecam tindakan kriminalisasi LGBT dan berdampak pada aspek-aspek lain diluar HAM.

Dikaitkan dengan perspektif HAM, pembelaan (advocacy) dan perlindungan (protection) hak-hak LGBT oleh NGO dan institusi di Malawi didasarkan pada Universalism Approach bahwa HAM sebagai nilai yang bersifat universal tidak bisa dimodifikasi untuk menyesuaikan sosial budaya sebuah negara. Dalam hal ini nilai-nilai HAM berlaku sama dimana pun serta dapat diterapkan pada masyarakat yang mempunyai latar belakang budaya dan sejarah yang berbeda. ${ }^{51}$ Sehubungan dengan penjelasan ini, NGO dan institusi yang pro LGBT di Malawi memaknai hak-hak LGBT sebagai suatu nilai dari HAM yang sifatnya universal. Mereka meyakini bahwa manusia itu memiliki hak yang sama tak terkecuali untuk orientasi seksual. Mereka tidak mempertimbangkan misalnya nilai-nilai lokalitas atau partikularitas yang berkembang di negara tersebut (dalam hal ini masyarakat di Malawi).

\section{Politik "Stick And Carrot" dalam Bantuan Luar Negeri Negara-Negara Pendonor}

Beberapa kriminalisasi yang dilakukan oleh polisi Malawi selain mengundang kecaman baik dari NGO domestik seperti CEDEP, CHRR dan sebagainya maupun NGO internasional seperti IGLHRC, kecaman untuk mencabut kebijakan kriminalisasi LGBT juga berdatangan dari organisasi-organisasi internasional seperti PBB yang diikuti Bank Dunia, IDA (International Development Assistance). ${ }^{52}$ Dalam perspektif hukum internasional, karena telah meratifikasi perjanjian-perjanjian internasional HAM

\footnotetext{
${ }^{51}$ A Ubaedillah dan Abdul Rozak. Pancasila, Demokrasi, HAM, dan Masyarakat Madani (pp.162). Jakarta:

Kencana Prenadamedia Group. 2017.

${ }^{52}$ Philip Browne. Op.cit. pp 26.
}

seperti International Covenant on Civil and Political Rights (ICCPR) dan International Covenant on Economic, Social and Cultural Rights (ICESCR), Malawi dinilai telah melakukan tindakan kontradiktif dengan komitmen perjanjian internasionalnya agar melindungi hak-hak semua warganya tanpa adanya diskriminasi terhadap jenis kelamin, warna kulit, ras, kaum minoritas dan sebagainya.

Selain aktor-aktor di atas, tindakan kriminalisasi LGBT juga memicu reaksi keras dari negara-negara pendonor Malawi. Reaksi kecaman dari negara-negara pendonor Malawi bisa menjadi topik krusial bagi kehidupan negara Malawi karena kecaman tersebut diikuti dengan ancaman pemotongan bahkan pencabutan bantuan luar negeri dari negaranegara donor padahal Malawi adalah negara miskin yang banyak mengandalkan bantuan luar negeri untuk kebutuhan pembangunan Malawi.

Merespon tindakan Malawi yang mengkriminalisasi para pelaku LGBT tahun 2009-2010, tahun 2011, negara-negara besar seperti AS, Inggris, Jerman dan sebagainya sebagai negara-negara pendonor utama bagi Malawi memberikan sinyal ancaman untuk mengurangi atau bahkan mencabut bantuan luar negerinya di Malawi. Dengan total mencapai US\$400 juta, bantuan luar negeri berpotensi hilang apabila pemerintah Malawi tidak mencabut kebijakan kriminalisasi pelaku LGBT. ${ }^{53}$ Tindakan Stick and Carrot dalam politik bantuan negara-negara donor tersebut menjadi ancaman nyata terhadap perekonomian dan pembangunan domestik Malawi mengingat $40 \%$ dari anggaran pembiayaan pembangunan pemerintah Malawi berasal dari bantuan luar negeri. Negara-negara donor memastikan jika Malawi tetap mempertahankan kebijakan kriminalisasi

\footnotetext{
${ }^{53}$ Claire Ngozo, "Malawi Donor Funding Threatened by Rights, Governance Issues," Inter Press Service, Maret 17, 2011 diunduh dari http://www.ipsnews.net/2011/03/malawi-donor-fundingthreatened-by-rights-governance-issues/
} 
pelaku LGBT, negara-negara donor tersebut akan mencabut atau setidaknya memotong porsi bantuan luar negerinya dalam jumlah yang besar.

AS, salah satu negara superpower yang mengakomodasi kebebasan dan perlindungan bagi pelaku LGBT sekaligus salah satu pendonor terbesar Malawi, memberikan respon penolakan terhadap kebijakan kriminalisasi LGBT di Malawi. Negara yang tercatat mendonorkan US\$200 juta dollar per tahun khususnya di bidang kesehatan ini bahkan secara eksplisit memberikan ancaman berupa penarikan bantuan luar negerinya melalui United States Agency for International Development (USAID) ke Malawi jika Malawi tidak merevisi kebijakan kriminalisasi pelaku LGBT. Semisal pada tahun 2012, AS melalui rezim Barack Obama mengutuk keras tindakan kriminalisasi yang dilakukan Malawi terhadap pelaku pernikahan sejenis tahun 2011. ${ }^{54}$

Sejalan AS, Inggris juga mengambil langkah yang serupa dengan AS. Menanggapi kasus-kasus kriminalisasi pelaku LGBT yang dianggap menyalahi HAM di Malawi, Oktober tahun 2011, Inggris yang merupakan negara eks penjajah Malawi melalui Perdana Menterinya, David Cameron mengumumkan bahwa negaranya akan memotong bantuan kepada Malawi sebesar US\$30 juta karena telah melakukan kriminalisasi pelaku homoseksual dengan hukuman berupa kerja kasar (hard labour) di penjara selama 14 bulan. ${ }^{55}$ Inggris melalui perwakilannya dalam kunjungan di salah satu negara Afrika, menegaskan bahwa negaranya akan akan memberantas kekerasan dan diskriminasi terhadap pelaku LGBT dalam bentuk apapun

\footnotetext{
54 David Smith, "Malawi to review homosexuality ban after US aid threat," The Guardian, Desember 9, 2011, diunduh dari https://www.theguardian.com/world/2011/dec/09/malawi -homosexuality-ban-review

55 Jakdphillip, "Tough Love: Britain Will Cut Aid to 'Anti-gay Nations," Time, Oktober 10, 2011, diunduh dari http://newsfeed.time.com/2011/10/10/tough-lovebritain-will-cut-aid-to-anti-gay-nations/
}

khususnya di negara-negara Afrika termasuk Malawi. Secara historis, Inggris memang telah menjadi kontributor utama dalam pembangunan berbagai bidang di Malawi. Setidaknya dalam kurun waktu dari 2008 hingga 2011, Inggris telah menggelontorkan dana sekitar US\$200 juta dollar ke Malawi dalam berbagai proyek pembangunan. ${ }^{56}$

Jerman, salah satu negara yang vokal menyuarakan dukungan dan perlindungan pelaku LGBT baik di lingkungan domestik maupun internasional ${ }^{57}$, juga mengambil tindakan yang tidak berbeda dari dua negara besar di atas. Tahun 2011, Jerman mengumumkan pemotongan bantuan luar negerinya ke Malawi sebagai respon atas kriminalisasi pelaku homoseksual dan pembatasan kebebasan pers di Malawi. Jumlah pemotongan bantuan yang ditujukan untuk anggaran pembangunan pun tidak tanggungtanggung mencapai 50\% dari jumlah yang dijanjikan sebesar US\$33 juta pada tahun 2011. Jerman meminta Malawi untuk mematuhi perjanjian HAM internasional yang diratifikasi oleh Malawi dalam kebijakan nasional terhadap pelaku LGBT. ${ }^{58}$

Ketergantungan akut Malawi terhadap bantuan luar negeri telah menganugerahkan bargaining power bagi negara-negara pendonor tersebut untuk memengaruhi bahkan menekan kebijakan-kebijakan Malawi seperti kebijakan kriminalisasi LGBT. Selain itu dengan bantuan luar negerinya, negara-negara donor mampu mempraktikkan konsep Stick and Carrot dalam politik domestik Malawi

\footnotetext{
${ }^{56}$ Travis Lupick, "U.K. aid policy makes things tougher for Malawi's gays," The Star, Oktober 17, 2011, diunduh dari

https://www.thestar.com/news/world/2011/10/17/uk_aid_ policy_makes_things_tougher_for_malawis_gays.html ${ }^{57}$ Shant Shahrigian, "German foreign policy works to support gay rights," DW, diunduh dari http://www.dw.com/en/german-foreign-policy-works-tosupport-gay-rights/a-15729932

58 Rex Chikoko, "Germany cuts aid to Malawi over homosexuality law," Afrika Review, Februari 4, 2011, diunduh dari http://www.africareview.com/news/Germany-cuts-aid-toMalawi-over-homosexuality-law/979180-1101482g3hbv8/index.html
} 
yang mana jika Malawi tidak mengikuti saran mereka agar mencabut kebijakan kriminalisasi LGBT negara-negara donor tersebut tidak segan untuk mencabut atau memotong porsi bantuan luar negerinya dalam jumlah yang besar. Bagi Malawi, ibarat dua sisi koin mata uang, bantuan luar negeri dari negara-negara maju menjadi sebuah curing recipe untuk pembangunan domestik namun di sisi lain, kedaulatan (sovereignty) Malawi dipertaruhkan. Alih-alih menghargai kebebasan, kedaulatan dan norma-norma domestik yang diimplementasikan oleh Malawi, negara-negara donor malah secara eksplisit mencoba mengintervensi kebijakan Malawi untuk mengubah dari "kriminalisasi" menjadi "dekriminalisasi” para pelaku LGBT.

\section{KESIMPULAN}

Dari pembahasan artikel ini dapat dipahami bahwa inkonsistensi pemerintah Malawi terhadap kebijakan LGBT dapat ditinjau dari dua dimensi. Pertama, inkonsistensi pemerintah Malawi berada pada dimensi antara proses pengambilan sebuah kebijakan (decision making process) dan pengaruh kelompok kepentingan domestik. Mereka bertindak untuk memberikan masukan bagi pengambil kebijakan melalui berbagai sarana seperti lobi, melalui media massa dan sebagainya baik untuk kepentingan kelompoknya maupun untuk kepentingan masyarakat. Tidak dipungkiri bahwa kelompok kepentingan satu dengan lainnya memiliki kepentingan yang saling berlawanan. Dalam kasus Malawi yakni kelompok RL dan NGO melakukan berbagai upaya untuk mempengaruhi pengambil kebijakan Malawi. Kedua, inkonsistensi pemerintah juga berada pada dimensi antara proses pengambilan sebuah kebijakan dan aktor luar negeri, yakni negara-negara pendonor melalui bantuan luar negerinya. Negara-negara pendonor menggunakan bantuan luar negerinya dengan menerapkan politik "stick and carrot" untuk mengintervensi kebijakan negara penerima.
Konsekuensinya ialah negara pendonor mampu mengubah perilaku hingga kebijakan negara penerima. Malawi adalah bukti dari konsekuensi politik ini. Merespon tindakan kriminalisasi LGBT, negara-negara pendonor menggunakan politik "stick and carrot" agar pemerintah Malawi mencabut kebijakan kriminalisasi LGBT.

Inkonsistensi Malawi dalam menerapkan kebijakan kriminalisasi LGBT di satu sisi bisa menjadi win-win solution bagi dua kubu secara temporer, meskipun dalam kerangka kebijakan ini juga menunjukkan bahwa Malawi telah menerapkan ambivalent policy atau kebijakan yang ambivalen. Malawi ingin menerapkan kebijakan kriminalisasi LGBT, tetapi di sisi lain Malawi juga khawatir terhadap eksistensinya di kancah internasional dan bantuan luar negeri dari negara pendonor. Tuduhan sebagai negara yang tidak menjunjung tinggi nilai-nilai HAM berpotensi menghambat diplomasi Malawi dalam pemenuhan kepentingan nasionalnya. Alasan lain adalah urgensi bantuan luar negeri yang menjadi sumber anggaran pembangunan. Berkurangnya atau bahkan dicabutnya bantuan luar negeri berpotensi menyebabkan krisis pembiayaan pembangunan domestik. Keberhasilan negara-negara donor mendikte kebijakan domestik Malawi melalui politik bantuan luar negerinya juga menunjukkan bahwa kedaulatan negara Malawi telah direduksi oleh negara-negara pendonor.

Tulisan ini juga memberikan gambaran lain bahwa desakan dari pihak RL yang meminta pemerintah Malawi untuk mempertahankan kebijakan kriminalisasi LGBT dan desakan dari NGO domestik dan negara-negara pendonor yang ingin mencabut kebijakan kriminalisasi LGBT merupakan sebuah proses yang berujung pada disfungsinya penegakan hukum di Malawi sehingga penerapan hukum pidana untuk pelaku LGBT tidak lagi objektif. Dalam hal ini, supremasi hukum Malawi dipertaruhkan. 


\section{REFERENSI}

\section{BUKU}

Heywood, Andrew. (2013). Politik: Edisi Keempat. Yogyakarta: Pustaka Pelajar.

Jasin, Johan. (2016). Hukum Tata Negara Suatu Pengantar. Yogyakarta: Deepublish.

Lancaster, Carol. (2007). Foreign Aid: Diplomacy, Development, Domestic Politics. Chicago and London: University of Chicago Press.

Mwakasungula, Undule. (2013). The LGBT situation in Malawi: an activist perspective, Chapter 13 of Corinne Lennox \& Matthew Waites (Human Rights, Sexual Orientation and Gender Identity in The Commonwealth: Struggles for Decriminalisation and Change. London: School of Advanced Study, University of London.

Subakti, Ramlan. (2010). Memahami Ilmu Politik. Jakarta: Gramedia Widiasarana Indonesia.

Thomson, Alex. (2016). An Introduction to African Politics Third Ed. Routledge.

Ubaedillah, A dan Abdul Rozak. (2017). Pancasila, Demokrasi, HAM, dan Masyarakat Madani. Jakarta: Kencana Prenadamedia Group.

Winarno, Budi. (2007). Sistem Politik Indonesia Era Reformasi. Jakarta: Buku Kita.

\section{THESIS}

Malamba, Manuel. (2012). The Controversy of Homosexuality: A Critical Look at The Issues That Make Legalizing Homosexuality in Malawi Difficult. Gothenburg: University of Gothenburg.

\section{ARTIKEL JURNAL}

Arisanto, Puguh T. (2017). Trade Controversy Amidst Tobacco Control Provisions: Dynamics on The Establishment of U.S Tobacco Control Act 2009. Jurnal Ilmiah Hubungan Internasional. Vol.13. No.2.

Chanika, Emmie, John L. Lwanda dan Adamson S. Muula. (2013). Gender, Gays and Gain: The Sexualised Politics of Donor Aid in Malawi. Africa Spectrum.Vol.48. No.1.

Randhawa, Guljinder K. (2012). Foreign Aid in Economic Development, International Journal of Computing \& Business Research. ISSN (Online): 2229-6166.

Robinson, Zoe. (2015). Lobbying in The Shadows: Religious Interest Groups in The Legislative Process. Emory Law Journal. Vol. 64. Issue. 4.

Wahyudi, Abdullah T. (2016). Universalitas dan Partikularitas Hak Asasi Manusia dalam Undang Undang Nomor 1 Tahun 1974 TentangPerkawinan. Al-Ahkam: Jurnal Ilmu Syariah dan Hukum. Vol. 1. No.1.

\section{LAPORAN TAHUNAN}

Afrobarometer. (2017). State of the Nation: Malawians' reflections on political governance. Malawi: University of Malawi.

Browne, Philip. (2017). Canaries in the Coal Mines : An Analysis for LGBTI Activism in Malawi, Country Report. Johannesburg: Other Foundation.

Home Office. (2016). Country Information and Guidance Malawi: Sexual orientation and gender identity. UK: Home Office.

International Gay and Lesbian Human Rights Commission. (2013). Africa Perspective: Newsletter 2013. New York: IGLHRC.

\section{KORAN ONLINE}

Chikoko, Rex. Nation Newspaper. (2010). Mutharika Criticises Gay Movement. diunduh dari http://www.gtzkenyahealth.com/press/down loads/PRESS\%20CLIPPINGS\%2027TH\%2 0APRIL\%202010.pdf

\section{ARTIKEL ONLINE}

Advocate. (2010). Four African LGBT Organizations Worth Supporting. diunduh dari https://www.advocate.com/artsentertainment/features/2010/08/11/fourafrican-lgbt-organizations-worth-supporting 
Antigaylaws. African Countries where Homosexuality is still a Crime. diunduh dari https://antigaylaws.org/regional/africa/

Apodaca, Clair. Oxford Research Encyclopedia of Politics. (2017). Foreign Aid as Foreign Policy. diunduh dari http://politics.oxfordre.com/view/10.1093/a crefore/9780190228637.001.0001/acrefore9780190228637-e-332?print=pdf

Banda, Mabvuto. Reuters. (2014). U.N. to launch legal challenge against Malawi antigay laws, Reuters. diunduh dari https://www.reuters.com/article/us-malawigays/u-n-to-launch-legal-challenge-againstmalawi-anti-gay-laws-

idUSBREA0K0H420140121

BBC News. (2010). Malawi pardons jailed gay couple. diunduh dari http://www.bbc.com/news/10190653

BBC News. (2015). Malawi 'suspends' antihomosexual laws. diunduh dari http://www.bbc.co.uk/news/world-africa35151341

Central Intelligence Agency. (2018). The World Factbook. diunduh dari https://www.cia.gov/library/publications/the -world-factbook/geos/mi.html

Chikoko, Rex. Africa Review. (2011). Germany cuts aid to Malawiover homosexuality law. diunduh dari http://www.africareview.com/news/German y-cuts-aid-to-Malawi-over-homosexualitylaw/979180-1101482-g3hbv8/index.html

China Embassy in Malawi. (2011). The Role of Religious Leaders in National Development -Keynote Speech by H.E. Ambassador Pan Hejun at the Religious Leaders Workshop of Malawi. diunduh dari http://mw.chinaembassy.org/eng/sghdhzxxx/t825097.htm

D, Saheb. Shareyouressays. 8 Important Functions and Role of Interest Groups. diunduh dari http://www.shareyouressays.com/knowledg e/8-important-functions-and-role-ofinterest-groups/112490

Dionne, Kim Y dan Dulani, Boniface. The Washington Post. (2016). This one graph shows the biggest threat to LGBT rights in Malawi. diunduh dari https://www.washingtonpost.com/news/mo nkey-cage/wp/2016/03/01/this-one-graphshows-the-biggest-threat-to-lgbt-rights-inmalawi/?utm_term $=.61 \mathrm{~b} 23 \mathrm{e} 50 \mathrm{c} 29 \mathrm{~b}$

Global Policy Forum. (2014). Development aid to Africa diunduh dari,

https://www.globalpolicy.org/social-andeconomic-policy/poverty-and-

development/poverty-and-development-inafrica.html

Human Rights Watch. (2012). Malawi: Courageous Move to Suspend Anti-Gay

Laws. diunduh dari https://www.hrw.org/news/2012/11/06/mal awi-courageous-move-suspend-anti-gaylaws

Jakdphillip. Time. (2011). Tough Love: Britain Will Cut Aid to 'Anti-gay Nations. diunduh dari

http://newsfeed.time.com/2011/10/10/toug h-love-britain-will-cut-aid-to-anti-gaynations/

Lupick, Travis. The Star. (2011). U.K. aid policy makes things tougher for Malawi's gays. diunduh dari https://www.thestar.com/news/world/2011/ 10/17/uk_aid_policy_makes_things_tough er_for_malawis_gays.html

Malawi Marriage Divorce and Family Relations Bill. (2015). diunduh dari https://www.giRLnotbrides.org/wpcontent/uploads/2015/03/MalawiMarriage-Divorce-and-Family-Relationsbill-2015.pdf

Mamba. (2016). Malawi religious leaders march against homosexuality and abortion. diunduh dari http://www.mambaonline.com/2016/12/08/ malawi-religious-leadeclrs-marchhomosexuality abortion/

Mamba. (2017). Public to be asked to give input on gay ban. diunduh dari http://www.mambaonline.com/2017/08/14/ malawi-public-asked-give-input-lgbtirights/

Mamba. (2016). Religious leaders meet with LGBTI community in Malawi. diunduh dari http://www.mambaonline.com/2016/08/03/ religious-leaders-meet-lgbt-communitymalawi/ 
Masina, Lameck. VOA. (2010). Malawians Debate Legalizing Gay Marriage. diunduh dari

https://www.voanews.com/a/malawiansdebate-issue-of-legalizing-gay-marriage-84777977/160359.html

Masina, Lameck. VOA. (2016). Malawi Court Annuls Government Suspension of AntiGay Laws. diunduh dari https://www.voanews.com/a/malawi-courtannuls-governments-suspension-on-antigay-laws/3188056.html

Masina, Lameck. VOA. (2012). Suspension of Anti-gay Law Draws Mixed Reaction in Malawi. diunduh dari https://www.voanews.com/a/suspensionof-anti-gay-law-draws-mixed-reaction-inmalawi/1541867.html

Ngozo, Claire. Inter Press Service. (2011). Malawi Donor Funding Threatened by Rights, Governance Issues. diunduh dari http://www.ipsnews.net/2011/03/malawidonor-funding-threatened-by-rightsgovernance-issues/

Nyasa Times. (2012). Petition against Malawi Govt suspension of anti-homosexuality laws. diunduh dari https://www.nyasatimes.com/petitionagainst-malawi-govt-suspension-of-antihomosexuality-laws/

Out Right Action International. (2014). UN Human Rights Committee Identifies Human Rights Violations Against Persons Based on Sexual Orientation in Malawi. diunduh dari https://www.outrightinternational.org/conte nt/un-human-rights-committee-identifieshuman-rights-violations-against-personsbased-sexual

Parliamentscot. (2017). Cross Party Group on Malawi. diunduh dari http://www.parliament.scot/CrossPartyGrou ps/Session5CrossPartyGroup/Minutes/Mala wi_20170510.pdf

Refugee Legal Aid Information. Malawi LGBTI Resources. diunduh dari http://www.refugeelegalaidinformation.org/ malawi-lgbti-resources

Reuters. (2012). Churches force Malawi to change tune on anti-gay law. diunduh dari https://www.reuters.com/article/us-malawi- gays/churches-force-malawi-to-changetune-on-anti-gay-lawidUSBRE8A70XJ20121108

Shahrigian, Shant. DW. (2012). German foreign policy works to support gay rights. diunduh dari http://www.dw.com/en/german-foreignpolicy-works-to-support-gay-rights/a15729932

Sibande, Lyson. Malawi Voice. (2012). Five Fallacies against Decriminalisation of Homosexuality in Malawi. Malawi Voice. diunduh dari http://www.malawivoice.com/2012/05/19/fi ve-fallacies-against-decriminalization-ofhomosexuality-in-malawi-40476/

Smith, David. The Guardian. (2011). Malawi to review homosexuality ban after US aid threat. diunduh dari https://www.theguardian.com/world/2011/d ec/09/malawi-homosexuality-ban-review

The Nation. (2012). Religious Leaders tip JB on homosexuality. diunduh dari http://mwnation.com/religious-leaders-tipjb-on-homosexuality/

Tsododo, Benny. The Herald. (2013). Gay parties Western, Not Human Rights. diunduh dari https://www.herald.co.zw/gay-partieswestern-not-human-rights/ 